\title{
Efficiency of a production line by application of the Kanban method
}

\author{
A Dimitrescu ${ }^{1}, \mathrm{C}$ Babiş $^{2}$, E Niculae $^{1}, \mathrm{O} \mathrm{Chivu}^{2}$ and L Dascălu ${ }^{2}$ \\ ${ }^{1}$ Theory of Mechanisms and Robots Department, Politehnica University, Bucureşti, România \\ ${ }^{2}$ Materials Technology and Welding Department, Politehnica University, Bucureşti, România \\ andrei_dimitrescu@yahoo.com
}

\begin{abstract}
This paper aims to present the study on the implementation of the Kanban system for the "bicycle wheel" benchmark in demand-side conditions. Due to variations in customer orders, production on the "Wheels" line is inconsistent, with work volume being also variable. In this way, dead times appear, production stagnating at some times, and in others being overstretched. There is a problem of finding a method of leveling the production, which also leads to a better performance of the Logistics department within the "Expedition" service. The work was carried out following a study with data provided by SC MECHROM INDUSTRY SRL, a member of the CAMPAGNOLO group, a bicycle manufacturing company, exclusively for performance sports.

Keywords: management, marketing plan, Kanban method.
\end{abstract}

\section{Introduction}

Kanban is a simple label that corresponds to a product reference. This tag sends information to production to make the necessary references before the stock reaches stage 0 .

Kanban is a legendary production concept and just-in-time system (JIT). According to Taiichi Ohno, the man credited with the JIT development, Kanban is a means by which JIT is accomplished. Kanban is a signaling system to trigger an action. As the name suggests, Kanban uses history cards to signal the need for an element [1].

The need to maintain a high rate of improvement has led Toyota to develop the Kanban system. Kanban has become an effective tool to support the operation of a production system. In addition, it has proven to be an excellent way to promote improvement, because the reduction in the number of Kanban in circulation has highlighted problem areas.

In 1940, Toyota began to study supermarkets to store and apply shelf and plant storage techniques, thinking that in a supermarket, customers get what they need at the right time and in the necessary quantity. Moreover, the supermarket only stored what it thought it would sell, and customers only took what they needed, the requirement in the future being ensured, because the supermarket replaced the missing products on the shelves. This has led Toyota to view a process as a client of previous processes as well as previous processes as a kind of shop [2].

An important factor in the success of production planning based on the "pushed" system is the predictability of customer demand over a long period of time. Kanban, by contrast, approaches the system "pulled", the demand being considered as part of what the customer is withdrawing. Thus, production is determined according to customer requirements. Given that supply times are long and demand is difficult to predict, the best way is to respond quickly to the observed demand. This is precisely the place where a Kanban system can help: it is used as an immediate signal of demand that 
propagates through the supply chain. Taiichi Ohno states that in order to be effective, the Kanban system must comply with strict usage rules:

$>$ stop products with defects before they reach further production processes,

$>$ the subsequent process withdraws only what is necessary from the previous process,

$>$ the exact production of the quantity withdrawn from the subsequent process,

$>$ leveling production,

$>$ can Kanban be used as a means of leveling production,

$>$ establishing and understanding the production process.

$>$ Kanban is a method for transferring products between different workstations.

The Kanban Card is the work tool that authorizes the transfer of materials during production, between successive machining operations.

A kanban must contain at least the following information: product data, condition of the material, quantity of the products in the container, destination of the container. You can also find other information such as: drawing of the piece, number of containers in the batch, information on the track of the parts in the production unit, information on the packaging and treatment of the parts.

Kanbanans are equally allocated to balanced systems. More cannabis is allocated in slow or higher workloads and the number of cannabis is reduced to workstations that are unloaded at their capacity.

The main functions of Kanban are:

$>$ provides information on material retrieval,

$>$ provide production information,

$>$ prevents excessive overproduction and transport,

$>$ represents a work order attached to the respective products,

$>$ prevents the production of defective products by identifying the process that generates defective parts,

$>$ highlight existing problems and ensure stock control.

A Kanban system can only work if the following rules are met:

Labeling. In a kanban loop, all containers containing parts will be labeled so that the condition of the parts in the container is known at all times.

Production. It will not be manufactured or transported without order. It is the consequence of the basic principle: the renewal of the actual "consumption" in the client section.

Priorities. Production ordering orders are the exact reflection of the "consumption" of the customer section, and it is imperative to observe the production ordering.

Size of manufacturing batch. The size of the manufacturing batch will be respected. This size is determined so that the manufacturing batch is optimal.

Abnormalities. All anomalies (machine fatigue, lack of workers, quality, etc.) are subject to particular labeling.

Also, a Kanban system must also be efficient, and for that it needs to be kept under control and modified whenever it is needed. There are 6 rules for it to be effective [3]:

$>$ no rebutting piece must come to the next stage of the trial. If there is a rebut piece downstream, it can stop the production stream and create stops on the production line,

$>$ the number of pieces in a box must be indentical to the one indicated on the Kanban card. If the number of pieces in a box is different, it can change the pace at which it occurs on the line, affecting leadtime,

$>$ the downstream process must withdraw exactly what it needs when it needs it. Any withdrawal without a withdrawal card is forbidden, as any withdrawal greater than the number of withdrawal cards,

$>$ the number of boxes produced by the upstream process must be equal to the number of boxes that are withdrawn from the downstream process,

$>$ the number of Kanban cards should be reduced when the process has been improved.

Figure 1 shows the operating diagram of the Kanban system. 


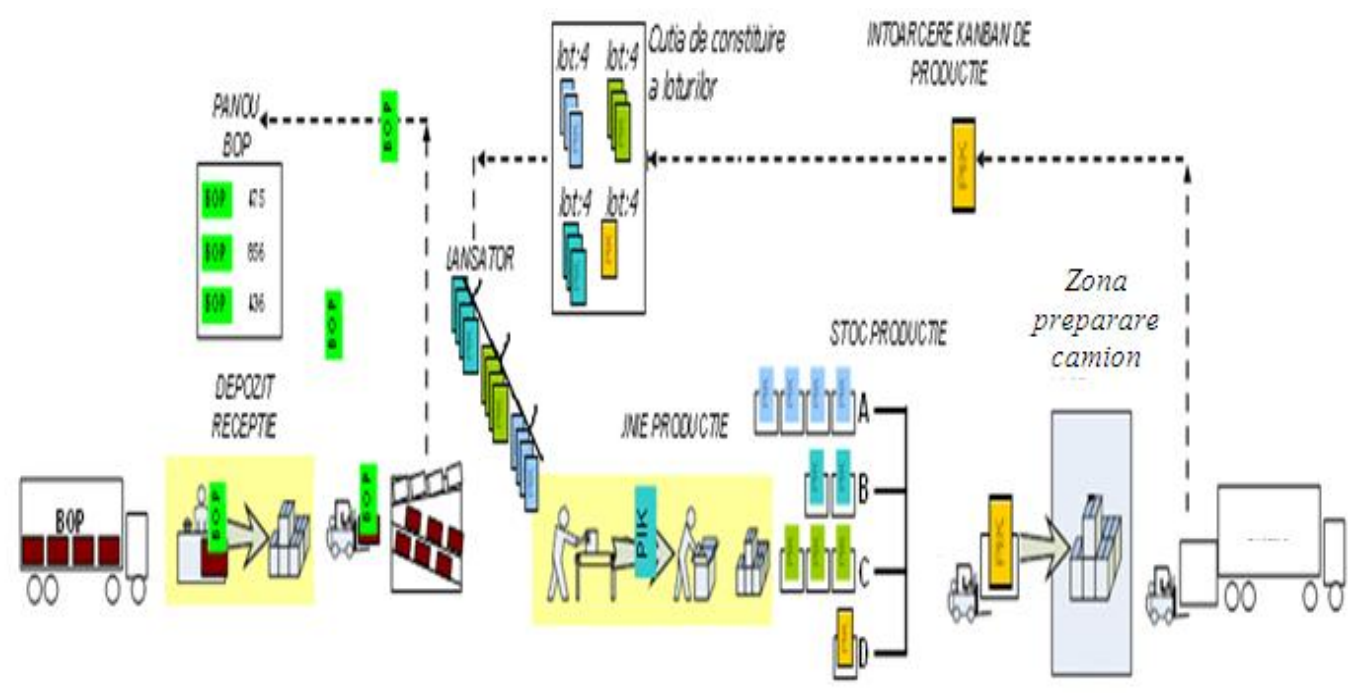

Figure 1. Kanban's operating scheme.

\section{Implementation methodology}

For each reference made and for each link of the process in question the initiation of a kanban chain is established as follows:

Collection of flow data to be organized:

$>$ flow characteristics,

$>$ characteristics of upstream workplaces (supplier),

$>$ characteristics of downstream jobs (customer),

$>$ mandatory characteristics: upstream position - downstream position.

Defining the operating parameters:

$>$ capacity and number of machines per post,

$>$ container capacity (minimum transfer batch),

$>$ minimum size of manufacturing batch for production,

$>$ size of the lot in progress,

Applying:

regular shopstock size.

$>$ production planning according to orders,

$>$ definition of kanban content,

$>$ defining the rules for the circulation of kanban and the planning of its operation.

Planning optimization:

$>$ adjusting the parameters according to the evolution of the system,

$>$ improving the current flow,

$>$ Kanbanuri allocation.

$>$ Kanbanans are equally allocated to balanced systems.

Multiple kanbanuri are allocated in slow processes or with a higher workload.

Determining the number of Kanbanuri is according to the formula:

$$
\mathrm{N}=(\mathrm{d} \times \mathrm{L}+\mathrm{Ss}) / \mathrm{C}
$$

where: $\quad \mathrm{N}$ - the number of kanbanuri,

$\mathrm{d}$ - average demand over a period,

$\mathrm{L}$ - manufacturing time,

Ss - safety stock,

C - container size. 


\section{Kanban Card}

The Kanban card used in the panel assembly line must contain a series of information that identifies the product for which it is designed, as well as the product line where the product is stored.

Writing must be visible and ligible so it can easily be spotted by production operators. Font size and type and font size and small font size can vary.

For the Kanban card from line 1, two types of color were used to differentiate the type of finished product, which helps the operator to identify the reference to be produced.

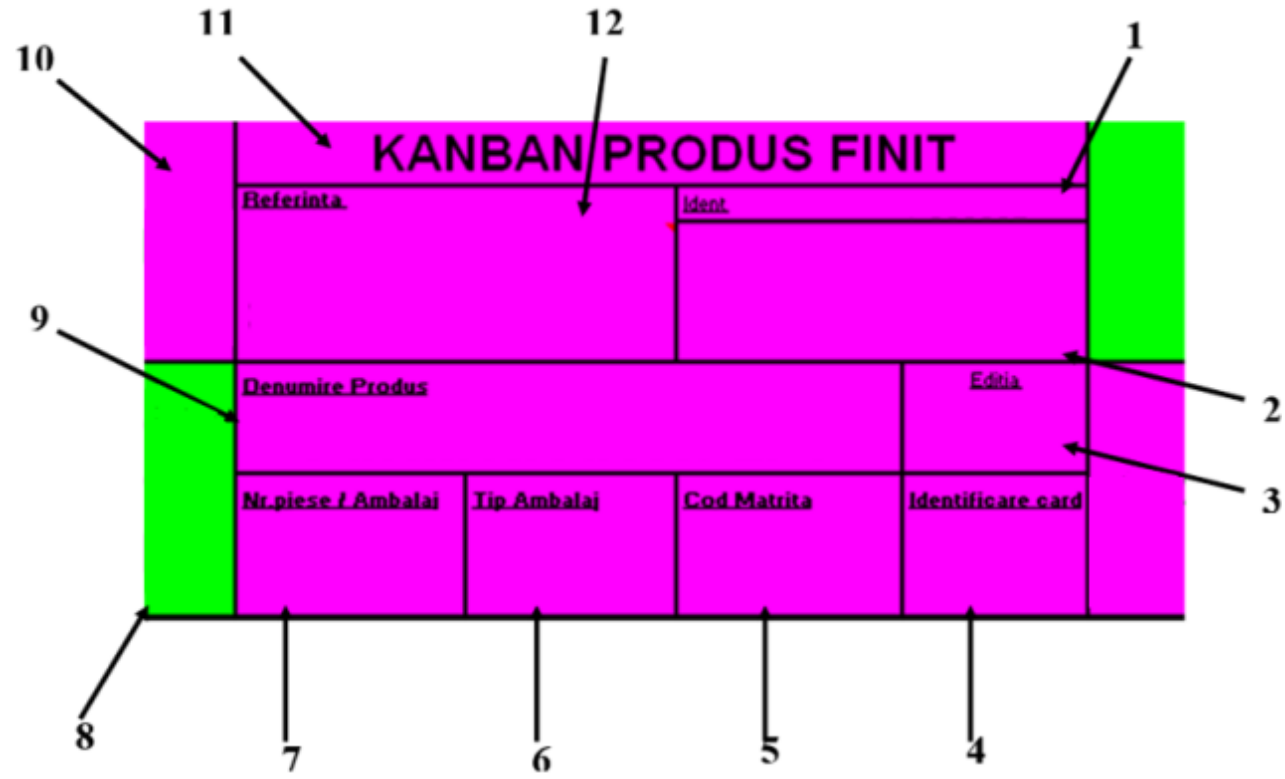

Figure 2. Kanban production card format.

The features to be used for identification are:

1. Ident - is the company's internal reference for a product, which is of two types: for finished products and semi-finished products.

2. Production line: Rolling line and assembly line.

3. The edition with which the Kanban Card was issued - the edition is unique for each card.

4. Card identification number - the identification number is unique for each card.

5. The quilting code used to make the product.

6. Type of packaging in which it is stored: box, container, pallet, carton kit.

7. Number of pieces to be put on the packaging.

8. Equipment version: type of bicycle phase, type of product: finished or semi-finished.

9. Customer Reference - is the code in the form of digits and / or letters by which the customer makes the order.

Figure 3 shows Kanban production flow and order information. The information comes from the logistics department, which is forwarded to the forklift. The forklift withdraws from the shopstock the necessary parts for the order and places them on the truck preparation area. As soon as the ordering time approaches, the pieces are moved to the train dedicated to the container containers and delivered to the customer. When the stocks are almost finished, the customer issues a new order to the supplier, reaching the Logistics department. Cards for withdrawn containers from shopstock are placed in the Kanban lot and are produced by the production line to rebuild the stocks. 


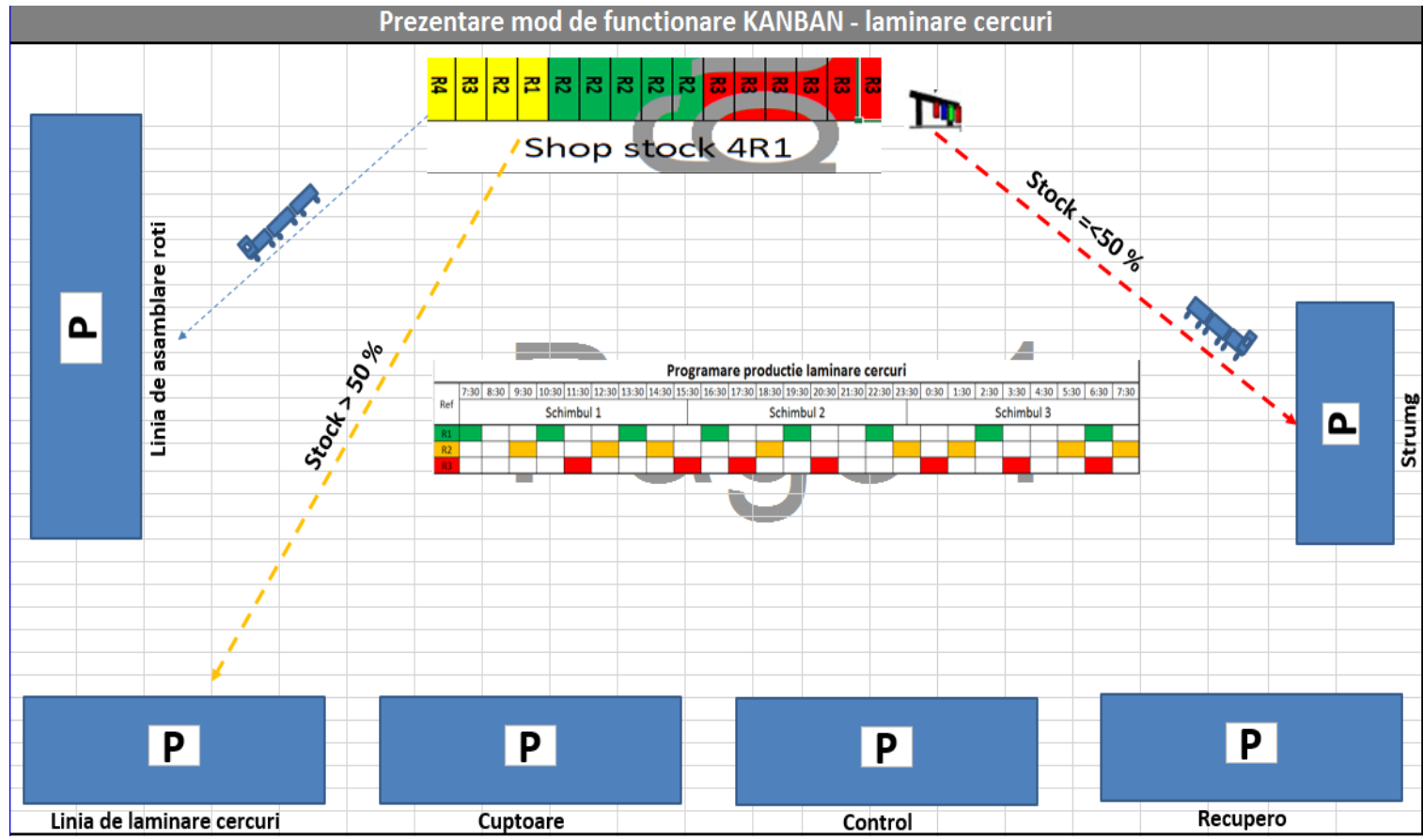

Figure 3. Kanban Production Flow and Ordering Order Information for the Assembly Line.

\section{Conclusions}

The purpose of this paper was to dimension the Kanban loop used to drive the production of bicycle wheels in conditions of customer demand fluctuation.

The main advantages of using the Kanban method were achieved by implementing it in the production system:

$>$ reduce the inventory,

$>$ reduces waste and scrap,

$>$ brings flexibility to production,

$>$ increase production,

$>$ reduces total cost.

The study is aimed at highlighting the characteristics of the systems and methods by which a manufacturing flow can be conducted. These range from "pushed" to the system used by big companies today, "fired".

The problem with MECHROM INDUSTRY, on the line of manufacturing the "Bicycle Wheels" milestone, has led to a thorough study to mitigate financial losses. The varied but variable volume requirement of the customer led to fluctuations on the assembly line.

In order for production to proceed at a steady pace, it was necessary to implement a leveling system for orders. This system is made using a card sequencer and a pool of customer variation absorption, Pool Stock.

Following the implementation of this leveling system of production, the following real improvements are achieved:

$>$ visual delivery management has emerged whereby both the Production $\neg$ Department and the Logistics Department can visualize the manufacturing and shipping performance;

$>$ the performance and efficiency of the "Wheels" assembly line $\neg$ increased by about $10 \%$ due to the visibility of the deliveries and the customer's requirement and the lower number of mold changes;

$>$ due to the Pool Stock tracking panel, oversized requests can be detected; 
Volume 1, Issue 1, 2019

ISSN: 2668-0416

Thoth Publishing House

$\rightarrow$ the missing parts per million (MPM) - the indicator by which the $\neg$ Logistics department evaluates the production department's performance was reduced to 0 . It follows that the production was not affected by the customer's orders;

$>$ establishing fixed retirement intervals for finished goods containers in the shopstock;

$>$ storage space has been reduced due to Pool Pool implementation;

$>$ the increase in daily production of "Wheels" with 25 pieces / day has generated an annual savings of about $7500 \mathrm{RON}$.

\section{References}

[1] Ohno, Taiichi (June 1988). Toyota Production System - beyond large-scale production. Productivity Press. pp. 29. ISBN 0915299143.

[2] Shingō, Shigeo (1989). A Study of the Toyota Production System from an Industrial Engineering Viewpoint. Productivity Press. pp. 228. ISBN 0915299178.

[3] Prioul, A. (July 2007). Basic principles of KANBAN, FAU-S-PSG-5023. France. 